Relational Aggression

\title{
DEMOGRAPHIC DETERMINANTS OF RELATIONAL AGGRESSION AMONG ADOLESCENT STUDENTS
}

\author{
Saima Riaz, Zaqia Bano, Razia Anjum*, Sami Ul Haque Ansari** \\ University of Gujrat, Gujrat Pakistan, *Government College Women University, Sialkot Pakistan, **Pakistan Institute of Living and Learning, Karachi Pakistan
}

\begin{abstract}
Objective: To determine the predictive relation of demographic variables with relational aggression.

Study Design: Cross sectional study.

Place and Duration of Study: Department of Psychology, University of Gujrat, Gujrat Pakistan, from Aug 2017 to Jan 2018. Methodology: A total of 612 adolescent students were selected with age 12-19 years from diverse academic institutes of Gujrat city. Urdu version of diverse adolescent relational aggression scale was used to measure relational aggression. Neural network analysis was carried out by using SPSS-21.

Result: The findings of this study revealed significant predictive relation of demographic variables (gender, birth order, family system, number of siblings and age) with relational aggression. The most important predictor of relational aggression in teenagers was birth order $0.249(100 \%)$, age $0.246(98.9 \%)$ siblings $0.242(86.3 \%)$, family system $0.166(66.8 \%)$ and gender 123 (49.6) respectively.

Conclusion: Demographic variables are the significant predictor of relational aggression. By managing the effects of these variables, adverse behavior of relational aggression can be controlled in adolescent students.
\end{abstract}

Keywords: Adolescents, Demographic variables, Predictive relationship, Relational aggression.

How to Cite This Article: Riaz S, Bano Z, Anjum R, Ansari SH. Demographic Determinants of Relational Aggression Among Adolescent Students. Pak Armed Forces Med J 2021; 71(5): 1633-1636. doi: https://doi.org/10.51253/pafmj.v71i5.3531

This is an Open Access article distributed under the terms of the Creative Commons Attribution License (https://creativecommons.org/licenses/by-nc/4.0/), which permits unrestricted use, distribution, and reproduction in any medium, provided the original work is properly cited.

\section{INTRODUCTION}

Human aggression is a social behavior. According to Baron and Richardson, ${ }^{1}$ aggression is any conduct which is aimed at damaging another individual who does not want to be mistreated. Aggression usually appears in different forms such as physical violence which involves hurting others bodily like beating, jolting, shooting, or stabbing; and oral aggression includes hurting others by degrading words (like name-calling, yelling, swearing, and screaming). One other form of aggression is relational aggression. Crick et al, ${ }^{2}$ who proposed the concept of relational aggression, believe that relational aggression is more damaging than physical aggression among adolescence. Relational aggression pertains to deliberately damaging another individual's social relations, inclusion within a group, or feelings of acceptance.

As relationships are extremely significant aspect of ones lives. Individuals have a propensity to consume their energies and resources in making and maintaining the relationships to others. Therefore, harm to the social relations causes great distress in an individual's life. Fundamentally, relational aggression stresses

Correspondence: Dr Saima Riaz, Department of Psychology, University of Gujrat, Gujrat Pakistan

Received: 27 Nov 2019; revision received: 20 Sep 2020; accepted: 06 Oct 2020 on the application of one's link to disrupt the others relationships. ${ }^{2}$ Struggles are made to harm the associations and these links are aimed for influencing somebody. The perpetrator misuses his or her associations as a foundation for getting control, to increase the communal endorsement, and to dispense ferocity. Oppressor's relations are tried to be a manipulated. Ferocious behaviors perhaps would be obvious in real activities both bodily and orally. Diverse oral methods are utilized such as distributing rumors, overlooking, segregation, gossip, and friendship exclusion. ${ }^{3}$ In short, relational aggression harms others by abolishing or fears to terminate the associations by upsetting their approval.

Aggression among friends and in educational institutes is a thoughtful problem. Adolescence is a growing age and in this significant period, young adults adopted some immoral patterns of behavior. During this period youngster may also get to indulge in behaviors like relational aggression. Relational aggression is not a novel type of violence. Many consider it to be a usual part of growth for kids and teenagers. ${ }^{4}$

Relational aggression is a freshly studied topic and has gained tremendous significance. Demographic variables like gender, age birth order etc. play important role in one's life. Literature supports the variation in aggression and relational aggression as well in 
reference to different demographics. Different use of relational aggression has been reported across gender. Female students are found to be more indulged in covert aggression as compared to overt. They less engaged in physical aggression. They usually use gossips, rumors, separation from friends, and different methods of abuse. ${ }^{5}$ Adolescents girls are more indulge in relational aggression as compared to boys. ${ }^{6}$ Moreover, a study supported the notion that males are more aggressive than females. ${ }^{7}$ Besides, research has also found aggression differences in reference to age. ${ }^{8}$ Birth order is another important factors. An association has been found between birth order and a propensity toward hostility. ${ }^{9}$ Teenage years are reflected as periods of turmoil residing amid childhood and adulthood. While passing through this age an individual goes through numerous vicissitudes both bodily as well as emotional.

This study aimed to investigate the effect of different demographic variables (gender, birth order, family system, age and number of siblings) on relational aggression in adolescent students.

\section{METHODOLOGY}

The cross sectional research study was carried out at department of Psychology, University of Gujrat, from August 2017 to January 2018.

A sample of 612 students were recruited from different academic institutes of Gujrat. The multistage random sampling technique was employed in the present study for selection of a good representative sample. List of private and public, middle and high schools was obtained by district education office Gujrat. Figures of students in public sector were obtained by district education office while students studying in private sector were estimated at the rate of $12 \%$ of public sector according to the instructions of district education office. The sample size was worked out by applying the Yamane formula at 0.05 level.

Inclusion Criteria: Adolescents from age 12-19, whom were studying in educational insti-tutes in Gujrat (schools, colleges and university) were included.

Exclusion Criteria: Adolescents under age 12 and above age 19 , adolescents not studying in any educational institute, and the adolescents with any physical disability and diagnosed psychological problems which hinder them in responding, were excluded from the current research.

Demographic information sheet was used for inquiring the related information about gender, birth order, family system, age and no. of siblings. For the assessment of relational aggression, the Urdu version of diverse adolescent relational aggression scale ${ }^{10}$, was used. The scale consisted of 27 items to illustrate relational aggression, acts and effects. There is no reversely scored item. All items are worded positively to rate the relational aggression. Responses have been rated on four-point Likert type format ranging from strongly disagree to strongly agree. Scale has a composite score; all the items are to taled for getting a score for relational aggression with high scores showing more relational aggression. Score range of the scale is 27-108. Reliability for the scale is 0.78 , and in the current study it was 0.8 .

Method and material applied in present investigation were examined and approved by the institutional review committee, University of Gujrat, Pakistan (IERB ltr no: UOG/ASRB/Psychology/02/7906). All recommendations of the board were incorporated in the present study. Permission was taken from the institutes authorities of the different educational institutes from where sample was to be drawn. Permission was also taken from parents of adolescent students through the institutes authorities. Sample selection was carried out in three stages. At first stage, 26 institutes were selected randomly by lottery method with equal allocation. Now these were considered sub-populations, and at second stage respondent were selected randomly from respective institutes. In the next stage, sections were selected randomly from all classes by lottery method. From each selected section attendance list was obtained by teacher. According to that list students were selected systematically by even odd method. Scales of study were given to students to be filled in, in a separate room. The total 640 adolescents were approached, 28 questionnaires were discarded, and remaining sample became 612 .

Neural network analysis by using SPSS-21 was applied for finding the predictive effects of afore said variables and their relative importance in the determination of relational aggression. It has been established that neural network is more suitable to practice instead of regression ${ }^{12}$. Further, the contribution of the demographic variables in regulating the relational aggression of adolescent students can be estimated in this analysis. In the first step demographic variables were put in factor and relational aggression was in dependent column. The training and testing cross entropy error and percent incorrect predication was examined with sample percentage. Finally, the neural network model explained the importance of indepen- 
dent variables for adjustment problems in adolescent students.

\section{RESULTS}

A total of 612 adolescent students of age range $12-19$ years with mean age $15.27 \pm 2.18$ years were selected. 366 were girls (59.8\%) and boys were 246 (40.2\%). Adolescent birth order ranges from 1-10. Number of sibling ranges from $0-14$, and $272(44.44 \%)$ adolescents were living in nuclear family system while 340 $(55.56 \%)$ were living in joint family system.

If the percent incorrect predications are constant in the training and testing it gives the confidence about the model as correct. In case of current research, the difference is very small for training and testing (TableI). The neural network model gives information about the relative importance of prediction of demographic factors for relational aggression. The importance can be shown in the Table-II.

Table-I: Model summary of neural network analysis $(n=612)$.

\begin{tabular}{l|c|c|c}
\hline \multicolumn{2}{l|}{ Cross Entropy Error } & \multicolumn{2}{|c}{ Percent Incorrect Predictions } \\
\hline Training & Testing & Training & Testing \\
\hline 343.86 & 150.56 & $36.5 \%$ & $37.3 \%$
\end{tabular}

Table-II: Predictive importance of independent factors $(\mathrm{n}=612)$.

\begin{tabular}{l|c|c}
\hline Parameters & Importance & Normalized Importance \\
\hline Gender & 0.12 & $49.6 \%$ \\
\hline Birth order & 0.25 & $100 \%$ \\
\hline Family System & 0.17 & $66.8 \%$ \\
\hline Age & 0.25 & $98.9 \%$ \\
\hline No. of Siblings & 0.21 & $86.3 \%$ \\
\hline
\end{tabular}

In result, a comprehensible neural network model appeared that elucidated the importance of independent variables for relational aggression among adolescent. The chart of importance shows that the results were dominated by birth order, followed by age, no. of siblings, family system and gender.

\section{DISCUSSION}

This study aimed at exploring the predictive relation of gender, birth order, family system, age and number of siblings on relationally aggressive behavior among adolescents with the endorsement of notion that all these are the determinants of relational aggression where birth order is the most salient. The concept of birth order was originated by Adler and he endorsed that it has a major role in the human life.7,12 Birth order variances are common because of siblings trying to contest for the attention of their parents by demanding roles inside the family. Previous researches endorse the results of current study. ${ }^{13}$
The current research implied that relational aggression varies with gender differences. The aforesaid notion is endorsed by previous findings. A research claimed that male delinquents inclined to practice physical hostility as a tool of harassment and pressure and as a prime technique to proclaim themselves over the victim. ${ }^{14}$ Further, males and females involve in relational aggression in a different way. ${ }^{6}$ Some researchers have contradictory findings when we talked about gender variations observed in relational aggression that female are more involved in relational aggression rather males use this type of mistreatment similarly or even more than females. ${ }^{6}$ Throwing more light on importance of demographic variable, a study conducted by Khan et al 15 found out that one third of school kids had hostile conduct positively linked to family variables and age. Moreover, a study reports contradictory findings about age and relational aggression relationship that it becomes stable after age. ${ }^{11,16}$ Current research supports predictive link of gender, ${ }^{7}$ age, $, 8,9,17,18$ and family structure with relational aggression.

\section{CONCLUSION}

Demographic variables are the significant predictor of relational aggression. By managing the effects of these variables, adverse behavior of relational aggression can be controlled in adolescent students.

\section{Conflict of Interest: None.}

\section{Authors' Contribution}

SR: Substantial, designing, acquisition, collection \& interpretation of data, ZB: Supervision and finalized the data, RA: Critical review and revision of data, SHA: Statistical analysis.

\section{REFERENCES}

1. Baron RA, Richardson DR. Human aggression 2nd ed. New York: Plenum; 1994, [Internet] Available from: https://www. annualreviews. (Accessed on Jan 18, 2018).

2. Crick NR, Grotpeter JK. Relational aggression, gender and socialpsychological adjustment. Child Dev 1995; 66(3): 710-722

3. Cheng CL. No blood means less harm? Relational aggression and peer rejection in adolescence. Bull of Educ Psych 2009; 40(3): 511-528.

4. Young EK, Nelson DA, Hottle AB, Warburton B. Relational aggression among students. Educ Dig 2011; 76(7): 24-29.

5. Andrews NCZ. On the association between self-reported ownand other-gender similarity and the use of physical and relational aggression in sixth grade children. Arch Sex Behav 2016; 45(1): 18171826.

6. Centifanti LCM, Fanti KA, Thomson ND. Types of relational aggression in girls are differentiated by callousunemotional traits, peers and parental over control. Behav Sci 2015; 5(1): 518-536.

7. Sultana S, Latif L. Adolescence Aggression as Related to Gender and Birth Order. J Sci 2013; 38(2): 97-107.

8. Khan FN. Age Differences in Expression of Aggression in Men and Women. Pak J Indep Stud Res 2006; 4(1): 1-5.

9. Seven S, Akif M. Social behaviors in nuclear and extended families children age 6 to 11 - a longitudinal study with turkish sample. Int J Humanit Soc Sci 2016; 6(2): 1-6. 


\section{Relational Aggression}

10. Riaz H. Impact of dysfunctional family system of externalizing behavior problems and mental health among adolescents. University of Sargodha, Sargodha; 2014, [Internet] Available from: https:// scholar.google.com/scholar?q=related:9PUiJTuRSCQJ:scholar. google.com/\&scioq=Impact+of+dysfunctional+family+system+of+ externalizing+behavior+\&hl $=$ en\&as_sdt $=0,5$

11. Lesinski G, Corns S, Dagli C. Application of an artificial neural network to predict graduation success at the united states military academy. Procedia Comput Sci (2016); 95(4): 375-382.

12. Gustafson C. The effects of birth order on personality. (Dissertation) Alfred Adler Graduate School. 2010, [Internet] Available from: http://alfredadler.edu/sites/default/files/Gustafson\% 20MP\%202010.pdf on 22.1.2019. (Accessed on Jan 18, 2018)

13. Birth Order and Aggressive Behavior. In Write www.work.com. 2004 [Internet] Available at: https://www.writework.com/essay/ birth-order-and-aggressive-behavior (Accessed on January 22, 2019).
14. Burnham JJ, Wright VH, Houser RA. Cyberbullying: emergent concerns for adolescents and challenges for school counselors. J Sch Coun 2011; 9(15): 4-10.

15. Khan M, Quadri SMA, Aziz S. Association of family structure and its environment with aggressive behavior of children (6-8 years) in a rural community. J Child Adolesc Behav 2014; 2(1): 125-30.

16. Orpinas P, McNicholas C, Nahapetyan L. Gender differences in trajectories of relational aggression perpetration and victimization from middle to high school. Aggress Behav 2015; 41(5): 401-412.

17. Mukhtar S, Mahmood Z. Prevalence and associated factors of relational aggression in educated adolescents. J Pak Psychiatr Soc 2016; 16(2): 2-5.

18. Hay DF, Paine AL, Perra O, Cook KV, Hashmi S, Robinson C, Kairis V, Slade R. Prosocial and Aggressive Behavior: A Longitudinal Study. Monogr Soc Res Child Dev. 2021 Jun;86(2):7-103. 